\title{
Interaction of polyaromatic hydrocarbons and metals on bioaccessibility and toxicity of arsenic
}

\author{
J.C. Ng, Q. Xia, S. Muthusamy, V. Lal \& C. Peng \\ Queensland Alliance for Environmental Health Sciences (QAEHS), The University of Queensland, \\ Brisbane, QLD, Australia
}

\begin{abstract}
We investigated the interaction effects of cadmium, lead and four PAHs on the toxicity of arsenic and each other. A simulated in vitro human digestive system and human liver cell-based assays were employed to determine their respective bioaccessibility, uptake and toxicity of individual toxicants and mixtures of up to all seven chemicals. Under most environmental conditions, additive effect can be assumed when assessing bioaccessibility of mixed arsenic, cadmium and lead with or without polyaromatic hydrocarbons whilst hepatic uptake was less than additive for cadmium mixed with arsenic/lead/pyrene/ benzo[a]pyrene. Toxicity in HepG2 cells including cytotoxicity, oxidative stress, genotoxicity and AhR (aryl hydrocarbon receptor) activation were determined. The interaction amongst mixtures vary depending on toxic endpoints, concentration and number of individual chemicals in the mixtures. Therefore, the traditional concentration addition or independent action model for health risk assessment may over or under estimate the risk of mixtures. This study has gained understanding of mixture interaction and helps to refine current risk assessment of mixed contaminants.
\end{abstract}

\section{INTRODUCTION}

Arsenic (As) is often found to co-exist with cadmium $(\mathrm{Cd})$, lead $(\mathrm{Pb})$ and organic toxicants such as polyaromatic hydrocarbons (PAHs) in contaminated sites (e.g. former gasworks sites). Information required for the risk assessment of arsenic and these other contaminants in this type of mixtures is lacking. A better understanding of potential interaction effects of mixtures with regard to their bioaccessibility and toxicity would inform the risk assessment process. A simulated in vitro human digestive system (Unified BARGE (Bioaccessibility Research Group of Europe) method (which is known as UBM)) and HepG2 cell-based assays were employed to measure the bioaccessibility, uptake and toxicity of individual toxicants and mixtures of up to all seven chemicals. Selected toxicants included $\mathrm{As}, \mathrm{Cd}, \mathrm{Pb}$, benzo[a]pyrene (B[a]P), naphthalene (Nap), phenanthrene (Phe) and pyrene (Pyr).

\section{METHODS/EXPERIMENTAL}

\subsection{Bioaccessibility and bioavailability}

United BARGE Method (UBM) (Denys et al., 2012) was used to measure bioaccessibility (BAC) of individual chemicals and in combinations of mixtures. Uptake by human liver cells (HepG2) is treated as a surrogate for bioavailability estimate.

\subsection{Toxicity interaction effects}

Toxicity interaction effects of individual chemicals and in mixtures were studied using HepG2 cells.
Biological end points included cytotoxicity (MTS assay), genotoxicity (micronucleus assay), oxidative stress (Nrf2 antioxidant pathway as determined in the ARE reporter-HepG2 cells) and AhR activation as measured by CAFLUX assay.

Individual dose-response curves obtained were used to selected dosages for the mixture experiments. A factorial design for combination of dosages was used for the interaction studies of mixed toxicants (Muthusamy et al., 2016a, 2016b).

Potential interaction effects between $\mathrm{As}, \mathrm{Cd}, \mathrm{Pb}$ and PAHs are illustrated in Figure 1. This study is aimed to investigate the relationship between bioaccessibility, cell uptake and toxicity effects of some biological endpoints.

\section{RESULTS AND DISCUSSION}

\subsection{Bioaccessibility and uptake in HepG2 cells}

Bioaccessibility of $\mathrm{As}, \mathrm{Cd}$ and $\mathrm{Pb}$ was not affected by PYR or B[a]P in spiked and aged soils. However, after UBM-extracted $\mathrm{As}, \mathrm{Cd}$ and $\mathrm{Pb}$ progressed to target organ cells (HepG2), uptake of Cd was inhibited by PYR or $\mathrm{B}[\mathrm{a}] \mathrm{P}$ probably due to the more damaged cell membrane whilst uptake of $\mathrm{As}$ and $\mathrm{Pb}$ was not affected. Arsenic and $\mathrm{Pb}$ interfered the sorption of $\mathrm{Cd}$ in soils, leading to an increase in $\mathrm{Cd}$ intestinal bioaccessibility. Pure solution results were in agreement with UBM extracted mixtures. Taken together, bioaccessibility of $\mathrm{As}, \mathrm{Cd}$ and $\mathrm{Pb}$ was not likely to be affected by PAHs due to distinct behavior of inorganic and organic contaminants in soils and solutions whilst accumulation 


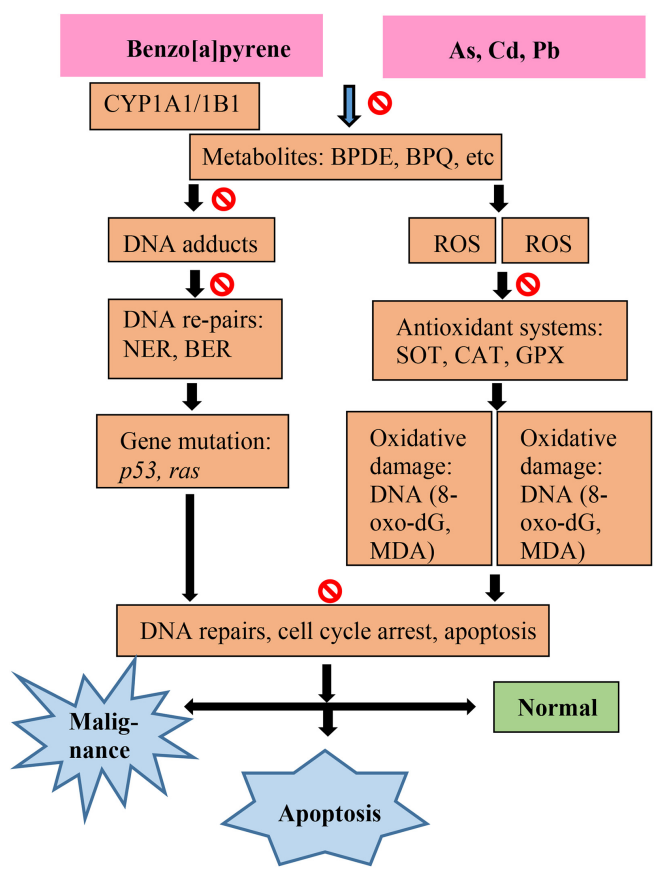

Figure 1. Potential interaction between $\mathrm{As}, \mathrm{Cd}, \mathrm{Pb}$ and $\mathrm{PAHs}$ using benzo[a]pyrene as an example, where indicates inhibition.

of metal/metalloid at toxic concentrations (e.g. Cd in this study) in hepatocytes might be inhibited by PAHs.

\subsection{HepG2 cell toxicity}

The cytotoxicity and interaction effects of binary to quaternary mixtures of $\mathrm{B}[\mathrm{a}] \mathrm{P}, \mathrm{As}, \mathrm{Cd}$ and $\mathrm{Pb}$ were found to be better predicted by using the combination index (CI)-isobologram method. The predicted interaction between these mixtures was synergism, additivity and antagonism at low, medium and higher concentration combinations of mixtures, respectively.

The mixture effect of the four selected PAHs and As, $\mathrm{Cd}$ and $\mathrm{Pb}$ on the Nrf2 antioxidant pathway (an indicator of oxidative stress response) was determined in the ARE reporter-HepG2 cells. The mixture study was carried out for binary, ternary, quaternary and sevenchemical combinations and the mixture effects were predicted using the CA model.

Binary or ternary mixtures of $\mathrm{As}, \mathrm{Cd}$ and $\mathrm{Pb}$ increased $\mathrm{MN}$ formation and $\mathrm{AhR}$ induced by $\mathrm{B}[\mathrm{a}] \mathrm{P}$ and the mixtures of PAHs decreased MN formation and $\mathrm{AhR}$ induction by $\mathrm{B}[\mathrm{a}] \mathrm{P}$. The mixtures at higher order, quaternary and seven chemical combinations of $\mathrm{As}, \mathrm{Cd}, \mathrm{Pb}$ and PAHs did not increase the genotoxicity of $\mathrm{B}[\mathrm{a}] \mathrm{P}$.

Toxicity studies with the bioaccessible fractions (UBM extracts) showed that the concentrations of toxicants were insufficient to induce cytotoxicity. The $\mathrm{Nrf} 2$ activation assay is more sensitive and hence useful to determine these chemicals response from UBM extracts with relatively low concentrations. The results from soil experiments showed that UBM method is useful to determine the bioaccessibility of metals but did not give good results for $\mathrm{B}[\mathrm{a}] \mathrm{P}$. The combination of bioaccessibility and bioassays could be useful for risk assessment of chemicals.

\section{CONCLUSIONS}

Under most environmental conditions, additive effect can be assumed when assessing bioaccessibility of mixed arsenic, cadmium and lead with or without polyaromatic hydrocarbons whilst hepatic uptake was less than additive for cadmium mixed with arsenic/lead/pyrene/benzo[a]pyrene. Bioaccessibility was also influenced by soil properties. Taken together, interaction should be interpreted individually for different physiological processes.

For toxicity evaluation, it was found that the CI method (Chou \& Talalay, 1984) could be better for predicting the mixture toxicity compared to that of concentration addition (CA) and independent action (IA) models. Whereas CA model may be appropriate for oxidative stress response assessment.

The interaction between these mixtures vary depends on toxic endpoints, concentration and number of individual chemicals in the mixtures. Therefore, the traditional CA or IA model for health risk assessment may over or under estimate the risk of mixtures. Further mechanistic studies are required to understand the observed effects in various toxic endpoints.

\section{ACKNOWLEDGEMENTS}

The research was funded by CRC CARE (project no. 3.1.01-11/12), the Chinese Science Council and UQ IPRS scholarships. QAEHS incorporating the former National Research Centre for Environmental Toxicology (Entox) is a partnership between Queensland Health and the University of Queensland.

\section{REFERENCES}

Chou, T.C. \& Talalay, P. 1984. Quantitative analysis of dose-effect relationships: the combined effects of multiple drugs or enzyme inhibitors. Adv. Enzyme. Regul. 22:27-55.

Denys, S., Caboche, J., Tack, K., Rychen, G., Wragg, J., Cave, M., Jondreville, C. \& Feidt, C. 2012. In vivo validation of the unified BARGE method to assess the bioaccessibility of arsenic, antimony, cadmium, and lead in Soils. Environ. Sci. Technol. 46(11): 6252-6260.

Muthusamy, S., Peng, C. \& Ng, J. 2016a. The binary, ternary and quaternary mixture toxicity of benzo[a]pyrene, arsenic, cadmium and lead in HepG2 cells. Toxicol. Res. 5(2): 703-713.

Muthusamy, S., Peng, C. \& Ng, J. 2016b. Effects of multicomponent mixtures of polyaromatic hydrocarbons and heavy metal/loid(s) effects on Nrf2-Antioxidant Response Element (ARE) pathway in ARE reporter-HepG2 cells. Toxicol. Res. 5(4): 1160-1171. 